\title{
Examining Trends in Type 2 Diabetes Incidence, Prevalence and Mortality in the UK between 2004 and 2014
}

DOI:

10.1111/dom.12964

Document Version

Accepted author manuscript

Link to publication record in Manchester Research Explorer

\section{Citation for published version (APA):}

Zghebi, S. S., Steinke, D., Carr, M., Rutter, M., Emsley, R., \& Ashcroft, D. (2017). Examining Trends in Type 2 Diabetes Incidence, Prevalence and Mortality in the UK between 2004 and 2014. Diabetes, Obesity and Metabolism, 19(11), 1537-1545. https://doi.org/10.1111/dom.12964

\section{Published in:}

Diabetes, Obesity and Metabolism

\section{Citing this paper}

Please note that where the full-text provided on Manchester Research Explorer is the Author Accepted Manuscript or Proof version this may differ from the final Published version. If citing, it is advised that you check and use the publisher's definitive version.

\section{General rights}

Copyright and moral rights for the publications made accessible in the Research Explorer are retained by the authors and/or other copyright owners and it is a condition of accessing publications that users recognise and abide by the legal requirements associated with these rights.

\section{Takedown policy}

If you believe that this document breaches copyright please refer to the University of Manchester's Takedown Procedures [http://man.ac.uk/04Y6Bo] or contact uml.scholarlycommunications@manchester.ac.uk providing relevant details, so we can investigate your claim.

\section{OPEN ACCESS}


Examining Trends in Type 2 Diabetes Incidence, Prevalence and Mortality in the UK between 2004 and 2014

\section{Salwa S Zghebi, PhD}

${ }^{1}$ Centre for Pharmacoepidemiology and Drug Safety, School of Health Sciences, Faculty of Biology, Medicine and Health, University of Manchester, Manchester Academic Health Sciences Centre (MAHSC), Manchester, UK

${ }^{2}$ Department of Pharmaceutics, Faculty of Pharmacy, University of Tripoli, Tripoli, Libya

\section{Douglas T Steinke, PhD}

${ }^{1}$ Centre for Pharmacoepidemiology and Drug Safety, School of Health Sciences, Faculty of Biology, Medicine and Health, University of Manchester, Manchester Academic Health Sciences Centre (MAHSC), Manchester, UK

\section{Matthew J Carr, PhD}

${ }^{3}$ Division of Psychology and Mental Health, School of Health Sciences, Faculty of Biology, Medicine and Health, University of Manchester, Manchester, UK.

\section{Martin K Rutter, MD}

${ }^{4}$ Division of Diabetes, Endocrinology and Gastroenterology, School of Medical Sciences, Faculty of Biology, Medicine and Health, University of Manchester, Manchester, UK

${ }^{5}$ Manchester Diabetes Centre, Central Manchester University Hospitals NHS Foundation Trust, Manchester Academic Health Science Centre (MAHSC), Manchester, UK

\section{Richard A Emsley, PhD}

${ }^{5}$ Centre for Biostatistics, Division of Population Health, Health Services Research \& Primary Care, Faculty of Biology, Medicine and Health, University of Manchester, Manchester Academic Health Science Centre (MAHSC), Manchester, UK.

Darren M Ashcroft, Prof (corresponding author)

${ }^{1}$ Centre for Pharmacoepidemiology and Drug Safety, School of Health Sciences, Faculty of Biology, Medicine and Health, University of Manchester, Manchester Academic Health Sciences Centre (MAHSC), Manchester, UK

First Floor, Stopford Building

Oxford Road, Manchester M13 9PT

E-mail: darren.ashcroft@manchester.ac.uk

- Word count (Abstract): 250

- Word count (Main text): 3,522

- Number of Tables: 2

- Number of Figures: 3 
Aims Contemporary data describing type 2 diabetes prevalence, incidence and mortality are limited. We aimed to (i) estimate annual incidence and prevalence rates of type 2 diabetes in the UK between 2004 and 2014; (ii) examine relationships between observed rates with age, gender, socio-economic status and geographic region; and (iii) assess how temporal changes in incidence and all-cause mortality rates influence changes in prevalence.

Methods Type 2 diabetes cases aged $\geq 16$ years between January 2004 and December 2014 were identified using the Clinical Practice Research Datalink (CPRD). Up to five individuals without diabetes were matched to diabetes cases based on age, gender and general practice. Annual incidence, prevalence and mortality rates were calculated per 10,000 person-years at risk $(95 \% \mathrm{Cl})$. Survival models compared the mortality rates in patients with and patients without type 2 diabetes.

Results Prevalence rates of type 2 diabetes increased from 3.21\% (3.19; 3.22) in 2004 to 5.26\% (5.24; 5.29 ) in 2014. Incidence rates remained overall stable throughout the study period. Higher incidence and prevalence rates were related to male gender and deprivation. People with type 2 diabetes were associated with higher risk for mortality (Hazard ratio 1.26 [1.20; 1.32]. Mortality rates declined in patients with and without diabetes throughout the study period. The incidence and prevalence of type 2 diabetes in patients aged 16-34years increased over time.

Conclusions The rising UK prevalence of type 2 diabetes over the last decade is likely to be explained by patients living longer rather than increasing type 2 diabetes incidence. 


\section{Introduction}

The prevalence of diabetes is increasing rapidly worldwide.[1-4] In 2016, the World Health Organization (WHO) reported that nearly 422 million adults live with diabetes; this is an increase in the global prevalence from $4.7 \%$ in 1980 to $8.5 \%$ in 2014.[5] Similarly, in the UK, diabetes is described as the fastest growing health condition[6] where prevalence has almost doubled over the last two decades.[7, 8] However, studies in the UK were often based on restricted local areas within the country;[9-11] estimated either incidence[12] or prevalence of type 2 diabetes[10] but not both simultaneously; or examined trends over a short study period.[11] A recent study examined UK trends in type 2 diabetes incidence and prevalence from 2000 to 2013 but it did not consider regional variation or the potential influence of changing mortality rates.[8]

Using UK-based primary care data, we aimed to (i) assess temporal trends in incidence and prevalence rates of type 2 diabetes stratified by gender, age and social-deprivation between 2004 and 2014; (ii) assess the contribution of incidence and mortality rates to observed prevalence; and (iii) compare differences in all-cause mortality between patients with type 2 diabetes and patients without diabetes.

\section{Methods}

Data Source

The Clinical Practice Research Datalink (CPRD) is an electronic database based on patients' primary care health records in the UK.[13, 14] The CPRD provides longitudinal anonymised data on patient demographics, clinical diagnoses, prescribed treatments, tests, referrals and linkage to external datasets and disease registries. Currently, CPRD holds research-quality data on 14 million patients registered with 697 general practices. Practice-level socio-economic data, as indicated by the index of multiple 
deprivation (IMD), is available. The IMD is a composite score constructed from the following domains of deprivation: finance, education, health, access to services and crime.[15]

The Quality and Outcomes Framework (QOF) scheme was introduced in 2004 to incentive UK general practices providing high-quality care including diabetes management.[16] The study period was from the QOF launch to maximise the quality of captured data.

Patient population

i. Examining incidence and prevalence

Patients aged $\geq 16$ years with $\geq 1$ diagnostic Read code for type 2 diabetes between 2004 and 2014 with data of an acceptable quality standard were included. Patients with codes for type 1 diabetes were excluded.

ii. Examining all-cause mortality

Patients with $\geq 1$ diagnostic code for type 2 diabetes, registered for $\geq 90$ days in an up-to-standard general practice, and aged $\geq 16$ years at diagnosis between 2004 and 2014 were identified. We excluded patients with any clinical code for type 1 diabetes. The up-to-standard criterion indicates that the practice data are of a high quality for use in research, based on the continuity of data recording and mortality rate compared with the expected range.[13,14] Up to five patients without diabetes were matched to each type 2 diabetes patient on age (birth year difference of $\leq 2$ years), gender and general practice.

Eligible patients were followed-up from their index date (the earliest type 2 diabetes diagnosis date) until the earliest date among the following events: date of the last data collection for the practice; patient transfer out of the practice; end of study (31/12/2014) or death. Comparators without diabetes were assigned the corresponding index date of the diabetes case and followed-up in the same manner. 
Statistical Analyses

\section{Incidence and prevalence rates}

Overall and annual crude incidence rates of type 2 diabetes were calculated by dividing the number of new cases diagnosed in a given year by the total population at risk. Calculated incidence rates were expressed per 10,000 person-years (PYR) at risk with $95 \%$ confidence intervals $(95 \% \mathrm{Cl}$ ). Overall and annual standardised incidence rates were calculated by age at diagnosis, UK country, or deprivation quintiles by adjusting for the respective factors. For instance, for estimation of gender-specific incidence rates by UK country, rates standardised by age and deprivation quintiles.

Overall and annual crude prevalence rates were calculated as percentage $(95 \% \mathrm{Cl})$ and per 10,000PYR at risk $(95 \% \mathrm{Cl})$. Rates were calculated as the number of existing type 2 diabetes patients in a given year (without restriction regarding past record of type 2 diabetes) divided by the total number of registered patients for that year. As with incidence rates, standardised prevalence rates were adjusted for age, UK country, or deprivation quintile depending on the stratification of interest.

To assess if the results will differ from annual rates, incidence and prevalence rates were also calculated over a fixed number of years using two-sets of intervals: i) over 6-/5-year (2004-2009 and 2010-2014 intervals), ii) over 4-/3-/4-year (2004-2007; 2008-2010; 2011-2014 intervals). Incidence and prevalence rates were also calculated in patients aged $16-34$ years and $\geq 35$ years. This was to assess the temporal changes in patients diagnosed with diabetes at young age.

\section{All-cause mortality rates}

The main demographic characteristics of the matched type 2 diabetes cases and patients without diabetes (comparators) were identified. Continuous variables were summarised as mean(SD) or median 
(interquartile range) and categorical variables as count (percentage). Annual crude mortality rates were calculated as the annual number of deceased type 2 diabetes cases or comparators divided by the personyears on that year. Cox proportional hazard models, stratified by the matching set identifier, were used to compare differences in all-cause mortality rates between patients with and without diabetes and estimate hazard ratio (HR) $(95 \% \mathrm{Cl})$. Schoenfeld residuals were used to test proportional hazards assumptions. As a sensitivity analysis, the model was restricted to patients registered in general practices that contributed to the full length of study 2004-2014.

Stata Software: release 14 (StataCorp, USA) was used for all analyses.

\section{Results}

\section{Incidence of type 2 diabetes}

The standardised incidence rate per 10,000 person-years (PYR) $(95 \% \mathrm{Cl})$ was $44.80(44.11 ; 45.49)$ in 2004 and remained overall stable up to 2013 before decreasing slightly to $36.89(36.19 ; 37.61)$ in 2014 . A peak in the number of incident cases was observed in 2006. By gender, the incidence of type 2 diabetes (T2DM) was higher in males than females (Table 1 and Supplementary Figure 1). Over the 11-year period, the mean incidence per 10,000PYR was $50.77(47.26 ; 54.28)$ in men, and $36.10(33.44 ; 38.77)$ in women. In 2004 , incidence rates were $52.10(51.04 ; 53.17)$ in men and $38.24(37.35 ; 39.13)$ in women. From 2007 onwards, incidence rates were fairly stable in both males and females. The incidence was higher in older age groups in both men and women (Figure 1 Panel I.a).

Incidence rates were overall higher in Wales and Northern Ireland in comparison to England and Scotland. Peak incidence in 2006 was less sharp in Wales than the other three countries (Figure 1 Panel I.b). Patients residing in the most socially-deprived areas had the highest incidence rates (Figure 1 Panel I.c). Estimated crude incidence rates were very similar to standardised rates (Supplementary Table 1). The incidence over 
year intervals was similar to annual rates as $45.0(44.72 ; 45.27)$ for the period $2004-2009$ and 41.73 (41.42;42.04) for 2010-2014. In patients aged $16-34$ years, incidence rates increased by $25 \%$ from 2.76 $(2.44 ; 3.08)$ to $3.44(3.04 ; 3.83)$ between $2004-2014$ (Supplementary Figure 2).

\section{Prevalence of type 2 diabetes}

The prevalence of type 2 diabetes increased steadily over time. Overall, standardised prevalence rates nearly doubled from $3.21 \%(3.19 ; 3.22)$ to $5.26 \%(5.24 ; 5.29)$ between $2004-2014$. By gender, the mean prevalence per 10,000 PYR was higher in men $(536,95 \% \mathrm{Cl}: 478.94 ; 592.37)$ than women $(377,95 \% \mathrm{Cl}$ : 338.69;415.60) (Table 1 and Supplementary Figure 3). In both genders, prevalence rates were positively related to age (Figure 1 Panel II.a), were higher in Wales and Northern Ireland (Figure 1 Panel II.b) and in areas of greater deprivation (Figure 1 Panel II.c). Estimated crude prevalence rates were very similar to the standardised rates (Supplementary Table 2). The prevalence over year intervals was similar to annual rates. In patients aged 16-34 years, the prevalence per 10,000PYR almost doubled from $10.56(9.67 ; 11.46)$ to $20.85(19.47 ; 22.23)$ in women and increased from $10.11(9.25 ; 10.96)$ to $16.78(15.55 ; 18.02)$ in men (Supplementary Figure 4).

\section{All-cause mortality}

We included 176,562 type 2 diabetes patients diagnosed between 2004 and 2014 and 881,901 matched controls in the analysis. Mean \pm SD age was $62.5 \pm 13.6$ years; $77 \%$ registered in English practices and $10 \%$ in Scottish practices; $16 \%$ from least deprived areas (IMD quintile 1); $21 \%$ from most deprived areas (IMD

quintile 5) (Figure 2 and Table 2). Among diabetes patients, $44 \%$ were prescribed lipid-regulating medications and $52 \%$ had hypertension versus $4 \%$ and $30 \%$ in controls. 
In the survival analysis, the cohort of matched diabetes cases and controls was followed for a total of 4,555,266 person-years (mean \pm SD follow-up for cases: $4.31 \pm 3.0$ years; controls: $4.30 \pm 3.0$ years). Mortality rates per 10,000 PYR declined between 2004 and 2014 from $319(309 ; 329)$ to $216(182 ; 257)$ in T2DM cases and from $251(247 ; 255)$ to $136(124 ; 150)$ per 10,000 PYRs in patients without diabetes (Figure 3 and Supplementary Table 3). Annual gender-specific mortality rates are calculated (Supplementary Figure 5). By the duration of follow-up, the excess risk associated with T2DM ranged between HR 1.28 $(1.23 ; 1.32)$ during the first year of follow-up and HR $1.47(1.32 ; 1.65)$ for follow-up of over nine years. This change of hazard over time affected the proportionality assumption and resulted in the need to report the risk of mortality at median follow-up interval (3.9 years). The proportionality of hazards was assessed annually up to $\leq 9$ years and for $>9$ years of follow-up. At median duration of follow-up, the overall risk of all-cause mortality was significantly higher in patients with T2DM compared to patients without diabetes (HR: 1.26, $1.20 ; 1.32)$. Schoenfeld residuals indicated the proportionality of the hazard function $(P=0.66)$. By gender, the excess risk was HR 1.24, $(1.17 ; 1.32)$ in males and HR $1.28(1.20 ; 1.37)$ in females. Similar results were found in the sensitivity analysis restricted to fully-contributing practices HR $1.27(1.21 ; 1.34)$ with proportional hazards $(P=0.27)$.

\section{Discussion}

\section{Main findings}

We have shown that type 2 diabetes prevalence rates rose by two-thirds while incidence rates were generally stable in the UK for the period 2004 to 2014 . Ageing population are the likely explanation for the observed increase in prevalence. Incidence and prevalence rates were markedly higher in men than women and this trend persisted throughout the study period after adjusting for age, UK nation, and socio- 
economic status. Older male patients living in deprived areas, were the most likely individuals to develop type 2 diabetes or have prevalent type 2 diabetes.

We found that all-cause mortality rates declined over the study period in all patients. Significantly higher mortality rates were observed in patient with type 2 diabetes compared to patients without diabetes. This finding builds up to previous reports that diagnosis with diabetes is associated with greater risk for mortality when compared to the general population.[17-19] The reason for the observed increases in mortality rates in 2006 is unclear. It is likely driven by the higher numerators (number of deaths) and denominator (person-years in analysis) as the 2006 cohort was the largest among all annual cohorts. For the increases in 2013, the Office for National Statistics reported a 1.5\% increase in deaths in 2013 compared to 2012.[20] The mortality gap between diabetes cases and controls however appear to widen in 2014. This is most likely driven by risen death rates in male diabetes cases unlike the decline observed with male and female controls and female cases (Supplementary Figure 5). Importantly, this gap narrows again in 2015 when analysis extended to 2015 (data not shown).

\section{Prior studies}

The reported findings add to the existing knowledge, as the majority of previous studies either studied the epidemiology of combined type 1 and type 2 diabetes;[7, 21] estimated incidence[12] or prevalence of type 2 diabetes[10] and not both simultaneously; covered a short study period[11] or were based on restricted local areas within the UK (which limits the generalisability of the findings for nationwide representation).[9-11] Moreover, few studies have assessed the association between incidence, prevalence and mortality in patients with type 2 diabetes.

For example, a Dutch study estimated these rates in type 2 diabetes between 1998 and 2000 [3]. However, the study was smaller $(\mathrm{N}=4,423)$ and mortality rates were compared to the general population 
(including patients with diabetes) which led to lower mortality rates ratios. The results showed an increasing prevalence but did not assess temporal changes in mortality and incidence. The study reported only overall crude and age-gender adjusted incidence rates per 10,000 patients of 22.0 and 22.7, respectively. The UK incidence were higher than that observed in the Netherlands as reported at 3.69 per $1,000 P Y R$ in men and 3.69 in women in 2000.[8]

A Canadian study reported a 69\% increase in the prevalence of diabetes between 1995 and 2005 which was attributed to increased incidence by $31 \%$ from 6.6 to 8.2 per 1,000 patients and a $25 \%$ decline in mortality.[21] This study examined all types of diabetes and mortality rates were not adjusted for socio-economic data. In comparison, our UK incidence was lower (4.5 per 1,000 patients in 2004). The higher diabetes prevalence in Canada over the UK has also been reported previously.[22] In a separate report, temporal trends in mortality rates in people with and without diabetes in Canada and the UK were compared.[17] Patients with diabetes had higher mortality risks, but these excess risks declined between 1996 and 2009 in both study cohorts (mortality rate ratios of up to $1.51(1.48 ; 1.54))$ perhaps reflecting improvements in general health and diabetes care.

By gender, the higher incidence and prevalence rates observed in men compared to women has been reported previously in England and Wales,[23] the UK,[8] Taiwan[2] and Europe.[4] In contrast, women are more likely to have type 2 diabetes in the Netherlands.(25)

Our finding that the incidence of T2DM at young age has increased over the past decade builds on to a previous study assessed the early incidence in patients <40 years during 1991-2010.[12]

We showed decreasing mortality rates which is in agreement with UK national reports in people with and without diabetes between 1983 and 2013[24] and in Scotland between 1993 and 2004.[9] Our findings also showed a $26 \%$ higher mortality risk in type 2 diabetes patients compared to those without diabetes confirming the mortality gap highlighted in many guidelines and reports on the association between diabetes and premature death.[18, 25] But, the observed excess risk was slightly lower than 
other reports. $[17,18]$ This difference may be due to improvements in care (for instance, in cardiovascular disease management) in the T2DM population over recent years and to the similar durations of follow-up between cases and matched controls. The latter (similar follow-up durations) was also observed in a recent report.[19] In our study, the similar duration of follow-up was mainly driven by the practicedetermined censor point (last date for contribution of data) which was the main censor point in the identified matched cohort.

This excess risk of mortality in diabetes patients was comparable to more recent studies.[19, 26] For example, a large study from Sweden, followed-up matched type 2 diabetes cases for 4.6 years and controls for 4.8 years and showed that the adjusted HR for all-cause mortality associated with diabetes was $1.15(1.14 ; 1.16)$ between 1998 and 2011.[19] The investigators attributed this comparatively low excess risk to improved medical care over time. In keeping with this idea, we showed that up to $28 \%$ and $44 \%$ of type 2 diabetes patients were prescribed antihypertensive and lipid-lowering therapies, respectively. Similar to our CPRD results, the latest National Diabetes Audit (NDA) data on complications and mortality (2012-2013)[27] reported: i) an 32\% excess risk for mortality in T2DM patients than the general population; ii) excess risk was higher in women; iii) the excess risk for mortality in patients with T2DM declined between the 2009-2010 and 2011-2012 audits, recommending that further studies are needed to examine the future patterns of this reduced trend.

Worldwide perspective on type 2 diabetes incidence and prevalence

The observed incidence plateau was seen previously in two relevant UK studies. Firstly, our overall stable incidence is comparable to the trend observed between 2004 and 2012 in a similar primary care database (THIN).[8] Secondly, the incidence rates of T2DM reported using CPRD were also stable between 20032006; increased between 2007-2009 before decreasing again in 2010. [12] 
Importantly, a recent study assessed whether the quality of recording of diabetes in the UK has affected the reported incidence and prevalence estimates of diabetes between 1995-2014.[28] It concluded that in contrast to previous reports, the incidence of diabetes, based on diagnostic codes, has not increased in the UK since 2004 suggesting that the choice of codes has a significant effect on incidence estimates. This important finding agrees with the approach adopted in our case definition strategy (excluding type 1 diabetes cases) aimed to minimise misclassification of T2DM.

International diabetes organisations have reported on the increasing prevalence rates of diabetes, but not necessarily incidence rates in all regions. [22, 29]

The number of people with diabetes is increasing in the UK and worldwide.[1-4] Our findings showed a rapidly increasing prevalence of type 2 diabetes in the UK over the last decade, which builds on the findings of relevant observational studies and national reports. $[8,9,25,30]$ The prevalence rates reportedly increased from $2.3 \%$ to $5.3 \%$ between $2000-2013$ in the UK; [8] from $5.8 \%$ to $8.5 \%$ between 2000-2007 in Taiwan;[2] and from 2.2\% to $2.9 \%$ between $1998-2000$ in the Netherlands.[3] It is important to note when comparing diabetes prevalence that in many countries prevalence rates are estimated from surveys from part of the country as very few countries have national registries. [22, 31] As some of the reported diabetes prevalence rates are survey-based [1] or based on self-reports.[4] This highlights the strengths of our findings as the UK prevalence estimates are based on national QOF data collected from general practices. In relation to the UK country-specific prevalence of T2DM, our findings showed that Wales had the highest standardised rates. This comes in agreement with the three most recent reports by Diabetes UK comparing the prevalence rates of diabetes in the four UK nations where Wales had the second highest rate after England in 2012, but the highest estimates in 2013 and 2014.[25] 
Potential influence of QOF and HbA1c-driven type 2 diabetes diagnosis

The overall stable incidence rates are similar to the trend reported previously in Taiwan between 2000 and 2007.[2] However, the transient increase in incident type 2 diabetes cases in 2006 is most likely to be attributed to the QOF changes implemented in April of the same year.[32] A second slight elevation in incidence was observed during 2012-2013 which may be related to the WHO recommendation in 2011 for using $\mathrm{HbA}_{1 \mathrm{c}}$ for type 2 diabetes diagnosis.[33]

\section{Clinical and policy implications}

The improved life expectancy in T2DM is likely to reflect improvements in population health and improvements in diabetes care in the UK,[17] This highlights the importance of effective strategies for screening and management of modifiable risk factors for cardiovascular disease as clearly demonstrated in clinical trials and observational studies.[34-36] For example, long-term follow-up of the Steno 2 trial cohort has shown that eight years of intensified, multifactorial, target-driven treatment of T2DM led to eight years of life gained.[36] Therefore the findings presented in our study have important implication for diabetes care. These findings provide additional impetus to tackle clinical inertia in the management of modifiable cardiovascular risk factors in T2DM. The findings should also inform social and health policymakers regarding tackling social deprivation and establishing effective preventative measures for T2DM that could avoid the morbidity, mortality and huge financial costs associated with T2DM.

\section{Strengths and limitations}

Our study has several strengths: firstly, this is the first large study to provide insight into the interrelationship between prevalence, incidence and mortality rates in type 2 diabetes patients across the UK. 
Secondly, the study had a large sample size representative of the UK population drawing on nearly 14 million CPRD patients. Thirdly, the study included patients from the four UK countries increasing the external validity of our findings. Fourthly, the selected study period was relevant to the current clinical practice scheme by starting from QOF introduction and up to 2014. Fifthly, our incidence and prevalence rates were adjusted for several factors including geographic nation within the UK. This enabled an assessment of country-specific temporal rates which may reflect on the effectiveness of local diabetes prevention and management strategies.

We acknowledge some limitations: firstly, our type 2 diabetes cohort was based on the cases diagnosed in the primary care database and represent consulting prevalence rates of type 2 diabetes. However, overall prevalence rates were similar to annual national estimations. [25, 30] Secondly, although the all-cause mortality analysis considered several important covariates, the possibility of residual confounding cannot be excluded.

\section{Conclusions}

We have shown that type 2 diabetes prevalence rates rose by two-thirds while incidence rates were generally stable in the UK for the period 2004 to 2014. Improvements in life expectancy were observed during the observation period which is likely to be the key driver of the observed increase in prevalence. Higher incidence and prevalence rates were observed in older males from more socially deprived areas. The incidence of type 2 diabetes at young age increased over the past decade. Patients with type 2 diabetes were at significantly higher risk for all-cause mortality than patients without diabetes. These data support ongoing efforts to improve the prevention and effective management of type 2 diabetes through social and medical intervention. 


\section{Acknowledgements}

SSZ would like to thank the Libyan Ministry for Higher Education for the scholarship provided for her PhD programme. This study is based on data from the CPRD obtained under license from the UK Medicines and Healthcare products Regulatory Agency (MHRA). However, the interpretation and conclusions contained in this paper are those of the authors alone. The study protocol was approved by CPRD's Independent Scientific Advisory Committee (ISAC) (reference: 15_149RMn). Parts of this study were presented at the $32^{\text {nd }}$ International Conference on Pharmacoepidemiology and Therapeutic Management (ICPE), Dublin, Ireland, 25-28 August 2016.

\section{Conflict of interests}

SSZ, DTS, MJC, RAE have no conflict of interest to disclose. DMA has received grant funding from Abbvie and served on advisory boards for Pfizer and GSK. MKR has received educational grant support from MSD and Novo Nordisk; modest stock ownership: GSK; and consultancy: Roche.

\section{Author Contributions}

DTS, DMA, MKR and SSZ contributed to the study design. SSZ extracted and analysed the data and drafted the manuscript, and all authors reviewed and edited the manuscript before submission. SSZ performed all the statistical analyses, supervised by DTS, DMA and MJC. DTS, DMA, MKR, RAE and SSZ contributed to the study protocol. SSZ had full access to all study data and takes responsibility for the integrity of the data and the accuracy of data analyses. SSZ's PhD sponsor (The Libyan Ministry for Higher Education) was not involved in the study design, analysis, interpretation of the data, or the preparation of this manuscript. 


\section{References}

[1] Onat A, Hergenc G, Uyarel H, Can G, Ozhan H. Prevalence, incidence, predictors and outcome of type 2 diabetes in Turkey. Anadolu kardiyoloji dergisi : AKD = the Anatolian journal of cardiology. 2006; 6: 314-321

[2] Lin CC, $\mathrm{Li} \mathrm{Cl}, \mathrm{Hsiao} \mathrm{CY}$, et al. Time trend analysis of the prevalence and incidence of diagnosed type 2 diabetes among adults in Taiwan from 2000 to 2007: a population-based study. BMC Public Health. 2013; 13:

[3] Ubink-Veltmaat LJ, Bilo HJG, Groenier KH, Houweling ST, Rischen RO, Meyboom-de Jong B. Prevalence, incidence and mortality of type 2 diabetes mellitus revisited: A prospective population-based study in The Netherlands (ZODIAC-1). Eur J Epidemiol. 2003; 18: 793-800

[4] Espelt A, Borrell C, Palencia L, et al. Socioeconomic inequalities in the incidence and prevalence of type 2 diabetes mellitus in Europe. Gac Sanit. 2013; 27: 494-501

[5] World Health Organization (WHO) media centre. Diabetes. [Fact sheet] 2016 [cited 201629 April]; Available from: http://www.who.int/mediacentre/factsheets/fs312/en/.

[6] Diabetes UK. State of the nation England - Challenges for 2015 and beyond. 2014 [cited 201515 April]; Available from:

https://www.diabetes.org.uk/Documents/About\%20Us/What\%20we\%20say/State\%20of\%20the\%20natio n\%202014.pdf.

[7] Gonzalez ELM, Johansson S, Wallander MA, Rodriguez LAG. Trends in the prevalence and incidence of diabetes in the UK: 1996-2005. J Epidemiol Community Health. 2009; 63: 332-336

[8] Sharma M, Nazareth I, Petersen I. Trends in incidence, prevalence and prescribing in type 2 diabetes mellitus between 2000 and 2013 in primary care: a retrospective cohort study. BMJ Open. 2016; 6: e010210

[9] Evans JMM, Barnett KN, Ogston SA, Morris AD. Increasing prevalence of type 2 diabetes in a Scottish population: effect of increasing incidence or decreasing mortality? Diabetologia. 2007; 50: 729-

732

[10] Harvey JN, Craney L, Kelly D. Estimation of the prevalence of diagnosed diabetes from primary care and secondary care source data: Comparison of record linkage with capture-recapture analysis. J Epidemiol Community Health. 2002; 56: 18-23

[11] Gatling W, Guzder RN, Turnbull JC, Budd S, Mullee MA. The Poole Diabetes Study: how many cases of Type 2 diabetes are diagnosed each year during normal health care in a defined community? Diabetes Res Clin Pract. 2001; 53: 107-112

[12] Holden SE, Barnett AH, Peters JR, et al. The incidence of type 2 diabetes in the United Kingdom from 1991 to 2010. Diabetes Obes Metab. 2013; 15: 844-852

[13] Herrett E, Gallagher AM, Bhaskaran K, et al. Data Resource Profile: Clinical Practice Research Datalink (CPRD). International Journal of Epidemiology. 2015; 44: 827-836

[14] Williams T, van Staa T, Puri S, Eaton S. Recent advances in the utility and use of the General Practice Research Database as an example of a UK Primary Care Data resource. Therapeutic Advances in Drug Safety. 2012; 3: 89-99

[15] Department for Communities and Local Government. The English Indices of Deprivation 2010. Crown; 2011 [cited 2013 21/08]; Available from: https://www.gov.uk/government/uploads/system/uploads/attachment data/file/6871/1871208.pdf. [16] Lester H, Campbell S. Developing Quality and Outcomes Framework (QOF) indicators and the concept of 'QOFability'. Quality in Primary Care. 2010; 18: 103-109 
[17] Lind M, Garcia-Rodriguez LA, Booth GL, et al. Mortality trends in patients with and without diabetes in Ontario, Canada and the UK from 1996 to 2009: a population-based study. Diabetologia. 2013; 56: 2601-2608

[18] Mulnier HE, Seaman HE, Raleigh VS, Soedamah-Muthu SS, Colhoun HM, Lawrenson RA. Mortality in people with Type 2 diabetes in the UK. Diabetic Medicine. 2006; 23: 516-521

[19] Tancredi M, Rosengren A, Svensson A-M, et al. Excess Mortality among Persons with Type 2 Diabetes. N Engl J Med. 2015; 373: 1720-1732

[20] Office for National Statistics (ONS). Deaths Registered in England and Wales: 2013. 2014 [cited 201712 February]; Available from:

https://www.ons.gov.uk/peoplepopulationandcommunity/birthsdeathsandmarriages/deaths/bulletins/de athsregistrationsummarytables/2014-07-16.

[21] Lipscombe LL, Hux JE. Trends in diabetes prevalence, incidence, and mortality in Ontario, Canada 1995-2005: a population-based study. Lancet. 2007; 369: 750-756

[22] International Diabetes Federation (IDF). IDF Diabetes Atlas - 7th Edition. 2015 [cited 201708 February]; Available from: http://www.diabetesatlas.org/.

[23] Newnham A, Ryan R, Khunti K, Majeed A. Prevalence of diagnosed diabetes mellitus in general practice in England and Wales, 1994 to 1998. Health Statistics Quarterly. 2002; 14: 5-13

[24] Office for National Statistics (ONS). Mortality in the United Kingdom, 1983-2013. 2014 [updated 11 December 2014; cited 201507 July]; Available from:

http://webarchive.nationalarchives.gov.uk/20160105160709/http://www.ons.gov.uk/ons/rel/mortalityageing/mortality-in-the-united-kingdom/1983-2013/mortality-in-the-united-kingdom--1983-2013.html.

[25] Diabetes UK. Facts \& Figures - Annual diabetes prevalence figures. 2015 [cited 201607 July]; Available from: https://www.diabetes.org.uk/About us/What-we-say/Statistics/.

[26] Forbes A, Murrells T, Sinclair AJ. Examining factors associated with excess mortality in older people (age $\geq 70$ years) with diabetes - a 10-year cohort study of older people with and without diabetes. Diabetic Medicine. 2016; 00: 000-000

[27] NHS Digital. National Diabetes Audit -2012-2013, Report 2. 2015 [cited 201726 January]; Available from: http://content.digital.nhs.uk/catalogue/PUB16496.

[28] Tate AR, Dungey S, Glew S, Beloff N, Williams R, Williams T. Quality of recording of diabetes in the UK: how does the GP's method of coding clinical data affect incidence estimates? Cross-sectional study using the CPRD database. BMJ Open. 2017; 7: e012905

[29] World Health Organization (WHO). Global Report on Diabetes. 2016 [cited 201711 February]; Available from: http://apps.who.int/iris/bitstream/10665/204871/1/9789241565257 eng.pdf.

[30] Health and Social Care Information Centre. Quality and Outcomes Framework. [cited 201607 July]; Available from: http://www.hscic.gov.uk/qof.

[31] N. Holman, B. Young, R. Gadsby. What is the current prevalence of diagnosed and yet to be diagnosed diabetes in the UK. Diabetic Medicine. 2014; 31: 510-511

[32] Calvert M, Shankar A, McManus RJ, Lester H, Freemantle N. Effect of the quality and outcomes framework on diabetes care in the United Kingdom: retrospective cohort study. BMJ. 2009; 338: b1870

[33] World Health Organization (WHO). Use of Glycated Haemoglobin (HbA1c) in the Diagnosis of Diabetes Mellitus. Abbreviated Report of a WHO Consultation. Geneva2011 [cited 201323 January]; Available from: http://www.who.int/diabetes/publications/diagnosis diabetes2011/en/.

[34] Bittner V, Bertolet M, Felix RB, et al. Comprehensive Cardiovascular Risk Factor Control Improves Survival The BARI 2D Trial. J Am Coll Cardiol. 2015; 66: 765-773

[35] Gaede P, Lund-Andersen H, Parving H-H, Pedersen O. Effect of a Multifactorial Intervention on Mortality in Type 2 Diabetes. N Engl J Med. 2008; 358: 580-591. 
[36] Gaede P, Oellgaard J, Carstensen B, et al. Years of life gained by multifactorial intervention in patients with type 2 diabetes mellitus and microalbuminuria: 21 years follow-up on the Steno- 2 randomised trial. Diabetologia. 2016; 59: 2298-2307 
Figure legends:

Figure 1: Gender-specific annual standardized incidence (Panel I) and prevalence (Panel II) rates per 10,000 PYR $(95 \% \mathrm{Cl})$ by a) age bands; b) UK nation; and c) neighborhood deprivation quintile (Q1: least deprived; Q5: most deprived).

Figure 2: Flow diagram for the identification of the matched cohort of patients with and without diabetes for the mortality analysis. T1DM: type 1 diabetes mellitus; T2DM: type 2 diabetes mellitus.

Figure 3: Crude annual mortality rates per 10,000 person-years (PYRs) $(95 \% \mathrm{Cl})$ for type 2 diabetes (T2DM) cases and matched patients without diabetes (controls) during follow-up. 
Table 1 Gender-specific annual standardised incidence and prevalence rates per 10,000 patients

\begin{tabular}{|c|c|c|c|c|}
\hline & \multicolumn{2}{|c|}{ Incidence } & \multicolumn{2}{|c|}{ Prevalence } \\
\hline Year & Males & Females & Males & Females \\
\hline 2004 & $52.10(51.04 ; 53.17)$ & 38.24 (37.35; 39.13) & $380.31(377.48 ; 383.13)$ & $268.56(266.22 ; 270.90)$ \\
\hline 2005 & 49.06 (48.05; 50.07) & $36.53(35.67 ; 37.39)$ & 419.48 (416.57; 422.39) & $297.43(295.01 ; 299.84)$ \\
\hline 2006 & $64.29(63.13 ; 65.44)$ & $46.93(45.96 ; 47.90)$ & 470.13 (467.07; 473.19) & 334.57 (332.02; 337.12) \\
\hline 2007 & $49.25(48.24 ; 50.26)$ & $35.28(34.44 ; 36.12)$ & 500.85 (497.69; 504.01) & $356.91(354.28 ; 359.55)$ \\
\hline 2008 & $49.87(48.85 ; 50.88)$ & $34.52(33.69 ; 35.35)$ & 526.61 (523.39; 529.84) & 373.25 (370.56; 375.93) \\
\hline 2009 & $52.02(50.98 ; 53.06)$ & $35.76(34.92 ; 36.61)$ & $552.90(549.59 ; 556.21)$ & $390.49(387.74 ; 393.25)$ \\
\hline 2010 & $51.59(50.54 ; 52.64)$ & $34.65(33.80 ; 35.50)$ & $580.39(576.95 ; 583.82)$ & $407.17(404.33 ; 410.01)$ \\
\hline 2011 & $47.90(46.87 ; 48.92)$ & 33.43 (32.59; 34.27) & $601.61(598.07 ; 605.14)$ & $422.71(419.78 ; 425.63)$ \\
\hline 2012 & 48.54 (47.50; 49.59) & $34.00(33.14 ; 34.86)$ & $613.24(609.62 ; 616.85)$ & $428.73(425.76 ; 431.71)$ \\
\hline 2013 & $51.26(50.14 ; 52.39)$ & $35.98(35.06 ; 36.90)$ & $621.23(617.43 ; 625.03)$ & $431.46(428.35 ; 434.57)$ \\
\hline 2014 & 42.59 (41.49; 43.68) & $31.83(30.91 ; 32.75)$ & $625.45(621.37 ; 629.52)$ & $437.28(433.94 ; 440.62)$ \\
\hline
\end{tabular}


Table 2: Baseline characteristics of the (1:5) matched type 2 diabetes cases and patients without diabetes (controls)

\begin{tabular}{|c|c|c|}
\hline Characteristic & $\begin{array}{c}\text { Cases } \\
\mathrm{N}=176,562\end{array}$ & $\begin{array}{c}\text { Controls } \\
\mathrm{N}=881,901\end{array}$ \\
\hline \multicolumn{3}{|l|}{ Age bands, N (\%) } \\
\hline $16-24$ years & $476(0.3)$ & $2,380(0.3)$ \\
\hline 25-34 years & $3,385(1.9)$ & $16,924(1.9)$ \\
\hline $35-44$ years & $13,903(7.9)$ & $69,512(7.9)$ \\
\hline 45-54 years & $32,089(18.2)$ & $160,418(18.2)$ \\
\hline $55-64$ years & $45,931(26.0)$ & $229,589(26.0)$ \\
\hline $65-74$ years & $44,872(25.4)$ & $224,227(25.4)$ \\
\hline$\geq 75$ years & $35,906(20.3)$ & $178,851(20.3)$ \\
\hline Female, $\mathrm{N}(\%)$ & $78,549(44.5)$ & $392,384(44.5)$ \\
\hline Follow-up (years) Median (IQR) & $3.9(4.8)$ & $3.8(4.9)$ \\
\hline Number of deaths, $\mathbf{N}(\%)$ & $20,312(11.5)$ & $79,951(9.1)$ \\
\hline \multicolumn{3}{|l|}{ Co-medications, $\mathrm{N}(\%)$} \\
\hline Diuretics & $20,640(11.7)$ & $7,952(0.90)$ \\
\hline$\alpha$ - adrenoceptor blockers & $7,527(4.3)$ & $2,762(0.31)$ \\
\hline$\beta$-adrenoceptor blockers & $41,507(23.5)$ & $17,906(2.03)$ \\
\hline Calcium-channel blockers & $41,471(23.5)$ & $20,474(2.32)$ \\
\hline ACE inhibitors & $49,628(28.1)$ & $19,903(2.26)$ \\
\hline ARBs & $17,175(9.7)$ & $6,564(0.74)$ \\
\hline Antiplatelet drugs & $45,741(25.9)$ & $19,424(2.20)$ \\
\hline Lipid-regulating drugs & $77,402(43.8)$ & $34,221(3.88)$ \\
\hline \multicolumn{3}{|l|}{ Comorbidities, N (\%) } \\
\hline Asthma & $21,329(12.08)$ & $83,865(9.51)$ \\
\hline COPD & $10,540(5.97)$ & $39,714(4.50)$ \\
\hline Hypothyroidism & $13,653(7.73)$ & $49,942(5.66)$ \\
\hline Osteoarthritis & $37,546(21.27)$ & $151,469(17.18)$ \\
\hline Chronic kidney disease & $13,527(7.66)$ & $46,618(5.29)$ \\
\hline Schizophrenia & $3,045(1.72)$ & $7,803(0.88)$ \\
\hline Dementia & $1,685(0.95)$ & $10,556(1.20)$ \\
\hline Depression & $40,072(22.70)$ & $162,361(18.41)$ \\
\hline Epilepsy & $2,710(1.53)$ & $13,483(1.53)$ \\
\hline Hyperlipidaemia & $34,607(19.60)$ & $101,579(11.52)$ \\
\hline Hypertension & $92,199(52.22)$ & $263,692(29.90)$ \\
\hline Peripheral vascular disease (PVD) & $5,538(3.14)$ & $15,804 \quad(1.79)$ \\
\hline Myocardial infarction & $12,194(6.91)$ & $31,744(3.60)$ \\
\hline Congestive heart failure & $7,357(4.17)$ & $18,052(2.05)$ \\
\hline Atrial fibrillation & $10,720(6.07)$ & $31,545(3.58)$ \\
\hline Stroke & $6,445(3.65)$ & $20,278(2.30)$ \\
\hline Transient ischemic accident (TIA) & $5,532(3.13)$ & $19,926(2.26)$ \\
\hline Cancer & $11,446(6.48)$ & $51,690(5.86)$ \\
\hline
\end{tabular}

ACE: angiotensin converting enzyme; ARB: angiotensin-II receptor blocker; COPD: chronic obstructive pulmonary disease; IQR: interquartile range. 


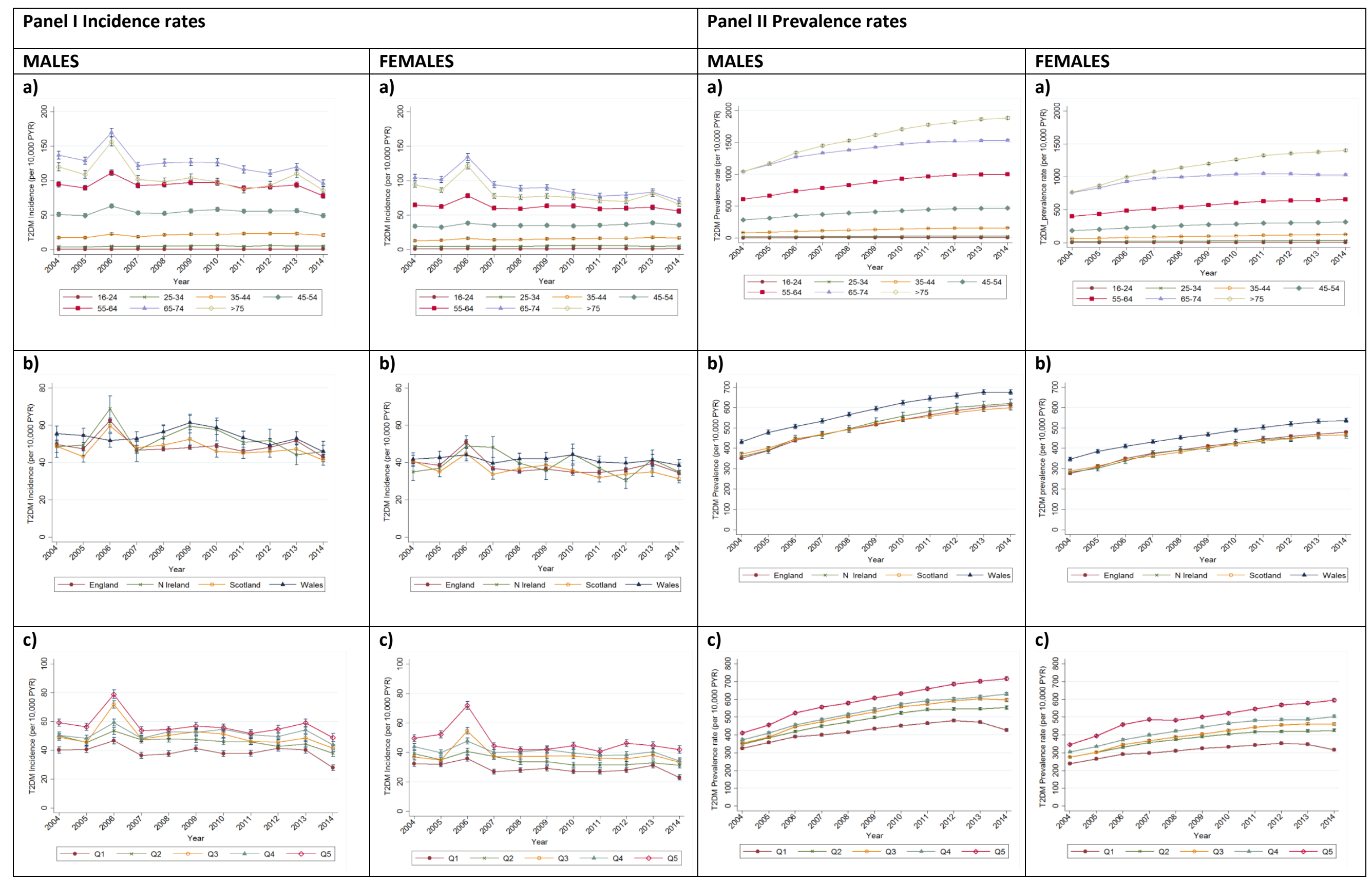









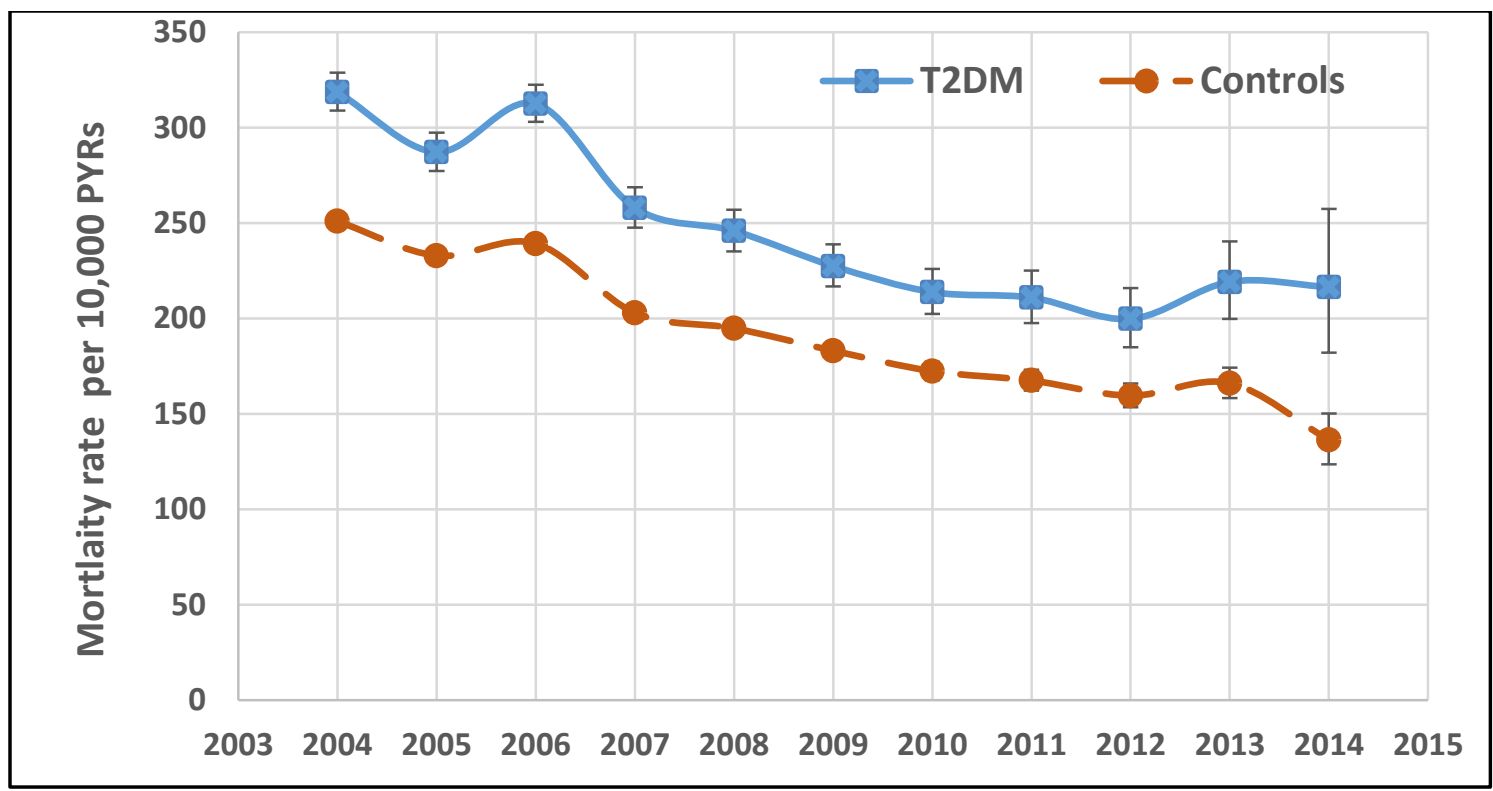

